\title{
Enriquecimento de bactérias anaeróbias oxidadoras de amônia - Anammox
}

\section{Enrichment of anaerobic ammonium oxidizing bacteria - Anammox}

\author{
Juliana Calábria de Araújo \\ Bióloga. Doutora em Hidráulica e Saneamento pela Escola de Engenharia de São Carlos da Universidade de São Paulo (EESC/USP). Professora adjunta do \\ Departamento de Engenharia Sanitária e Ambiental da Universidade Federal de Minas Gerais (DESA/UFMG)
}

\section{Ana Paula Campos}

Bióloga. Bolsista DTI do Conselho Nacional de Desenvolvimento Científico e Tecnológico (CNPq) no projeto Finep: "Caracterização e quantificação de microrganismos em sistemas de Tratamento de Efluentes líquidos", desenvolvido no DESA/UFMG. Mestranda do DESA/UFMG

\section{Marcos Messias de Souza Correa \\ Biólogo. Bolsista AT-NS do CNPq no projeto Finep, desenvolvido no DESA/UFMG}

\section{Eduardo Carvalho Silva}

Biólogo. Bolsista de Iniciação Científica do CNPq no projeto Finep, desenvolvido no DESA/UFMG

Marcos Von Sperling

Engenheiro Civil e Sanitarista. Doutor em Engenharia Ambiental pela Universidade de Londres. Professor Titular do DESA/UFMG

\section{Carlos Augusto de Lemos Chernicharo}

Engenheiro Civil e Sanitarista. Doutor em Engenharia Ambiental pela Universidade de Newcastle upon Tyne, Reino Unido. Professor associado do DESA/UFMG

\begin{abstract}
Resumo
Bactérias anaeróbias oxidadoras de amônia (bactérias Anammox, do inglês anaerobic ammonium oxidizing bacteria) foram enriquecidas em reator em batelada sequencial (RBS), a partir de lodo proveniente de um sistema convencional de lodos ativados tratando esgoto doméstico de Belo Horizonte (MG). Após três meses de cultivo, atividade Anammox foi detectada no sistema pelo consumo de quantidades estequiométricas de $\mathrm{NO}_{2}{ }_{2}^{-}$e $\mathrm{NH}_{4}^{+}$. Análises de hibridação in situ fluorescente (FISH, do inglês fluorescent in situ hybridization) confirmaram a presença de bactérias Anammox, provavelmente Candidatus Brocadia anammoxidans, e revelaram que estas representavam 53\% do total de células (após 6 meses de cultivo). O desempenho do reator ao longo dos sete meses de operação demonstrou remoção quase que total de nitrito, baseada em concentração afluente de 61 a 95 mg N-NO ${ }_{2} / L^{2}$. A eficiência máxima de remoção de

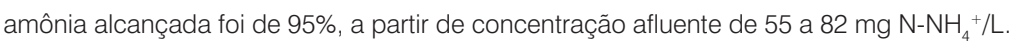

Palavras-chave: Candidatus Brocadia anammoxidans, FISH, inóculo, lodos ativados, nitrito, reator em bateladas sequenciais

\begin{abstract}
Anaerobic ammonium-oxidizing (Anammox) bacteria were enriched from sludge collected at a conventional activated sludge system treating domestic wastewater of Belo Horizonte(MG), Brazil, employing a sequencing batch reactor (SBR). After three months of cultivation, Anammox activity was detected in the system by the consumption of stoichiometric amounts of $\mathrm{NO}_{2}$, and $\mathrm{NH}_{4}{ }^{+}$. Fluorescent in situ hybridization (FISH) results revealed the presence of Anammox bacteria (probably Candidatus Brocadia anammoxidans) and showed that they accounted for $53 \%$ of the total bacterial population (after 6 months of cultivation) The reactor performance during the seven months of operation showed a near perfect removal of nitrite, based on the influent $\mathrm{NO}_{2}-\mathrm{N}$ concentration of $61-95$ $\mathrm{mg} / \mathrm{L}$. The maximum ammonia removal efficiency was $95 \%$ from the influent $\mathrm{N}^{-\mathrm{NH}_{4}}{ }^{+}$concentration of $55-82 \mathrm{mg} / \mathrm{L}$.
\end{abstract}

Keywords: Candidatus Brocadia anammoxidans, FISH, inoculum, activated sludge, nitrite, sequencing batch reactor. 


\section{Introdução}

O nitrogênio é um dos principais nutrientes que o tratamento de águas residuárias tenta remover, objetivando evitar a poluição das águas superficiais. A remoção biológica de nitrogênio geralmente é realizada pela combinação dos processos de nitrificação autotrófica e desnitrificação heterotrófica. Essas reações são conhecidas desde muito tempo e vêm sendo aplicadas com sucesso na maioria dos sistemas modernos de tratamento de águas residuárias (EGLI et al., 2001). Há mais de uma década, foi verificado, em reator de leito fluidizado, um processo microbiológico novo para a remoção de nitrogênio (MULDER et al., 1995). Esse processo foi denominado de oxidação anaeróbia da amônia (Anammox, do inglês anaerobic ammonium oxidation) e envolve a oxidação anaeróbia do íon amônio a nitrogênio gasoso, sob condições anóxicas, usando o nitrito como aceptor final de elétrons (VAN DE GRAAF et al., 1996). O modo de crescimento autotrófico dessas bactérias (em combinação com a necessidade de alta manutenção da célula devido ao crescimento muito lento) resulta em uma estequiometria que apresenta um baixo rendimento de biomassa (STROUS et al., 1998), conforme a

$\mathrm{NH}_{4}^{+}+1,32 \mathrm{NO}_{2}^{-}+0,066 \mathrm{HCO}_{3}^{-}+0,13 \mathrm{H}^{+} \rightarrow 1,02 \mathrm{~N}_{2}+0,26 \mathrm{NO}_{3}^{-}+$ $0,066 \mathrm{CH}_{2} \mathrm{O}_{0,5} \mathrm{~N}_{0,15}+2,03 \mathrm{H}_{2} \mathrm{O}$

Equação 1

Os organismos Anammox estão classificados no filo dos Planctomicetos, cinco dos quais foram denominados provisoriamente de Candidatus Brocadia anammoxidans, Candidatus Kuenenia stuttgartiensis, Candidatus Scalindua wagneri, Candidatus Anammoxoglobus propionicus (KARTAL et al., 2007) e Candidatus Jettenia asiatica (QUAN et al., 2008), que se constituem em um grupo interessante de bactérias com muitas propriedades raras ou únicas. Elas apresentam morfologia de cocos com diâmetro menor que $1 \mu \mathrm{m}$ (VAN NIFTRIK et al., 2004), tempo de duplicação de aproximadamente 11 dias e são fisiologicamente distintas dos outros membros do grupo, pois são anaeróbias e quimiolitoautótrofas.

Recentemente, vários trabalhos têm reportado a detecção e identificação de bactérias Anammox em diferentes ambientes (nas diversas partes do mundo), tais como em lodos oriundos de sistemas de tratamento de águas residuárias (SCHMID et al., 2003; DAPENA-MORA et al., 2004), em sedimentos marinhos (DALSGAARD; THAMDRUP, 2002; TAL; WATTS; SCHREIER, 2005), em ambientes de água doce (JETTEN et al., 2003; SCHUBERT et al., 2006) e em águas salobras (SANCHEZ-MELSIÓ et al., 2009). Não obstante, a maioria das bactérias Anammox ainda não foi isolada, portanto, técnicas moleculares, como a hibridação in situ fluorescente (FISH, do inglês fluorescent in situ hybridization) e a reação em cadeia da polimerase (PCR), são essenciais para o futuro das pesquisas com essas bactérias (SCHMID et al., 2005).
O processo Anammox, em combinação com o processo SHARON (sistema composto de um único reator usado para promover intensa remoção de amônia até nitrito, do inglês Single reactor system for High activity Ammonia Removal Over Nitrite), vem se constituindo em uma nova alternativa para remover compostos nitrogenados de efluentes contendo alta concentração de amônia e pequenas quantidades de matéria orgânica biodegradável. A aplicação desses dois processos combinados reduziria em $60 \%$ a demanda por oxigênio (comparado com o processo convencional de nitrificação) e eliminaria a necessidade de adição de fonte externa de carbono (desnitrificação convencional) (VAN DONGEN; JETTEN; VAN LOOSDRECHT, 2001).

Não obstante, a aplicação do processo Anammox está limitada pela disponibilidade de biomassa Anammox e pela dificuldade associada a cultivar e manter grandes quantidades dessas bactérias. $O$ isolamento e enriquecimento das Anammox, a partir de uma comunidade bacteriana mista, requer a otimização das condições que favorecem o processo Anammox, enquanto limita o crescimento dos outros tipos microbianos. Diferentes reatores vêm sendo utilizados com sucesso para desenvolver a atividade Anammox, tais como reator de leito fluidizado (MULDER et al., 1995; VAN DE GRAAF et al. 1996), reator em batelada sequencial (RBS) (STROUS et al., 1998; VAN DONGEN; JETTEN; VAN LOOSDRECHT, 2001), entre outros. Dentre eles, o RBS vem sendo recomendado para o enriquecimento das Anammox pela simplicidade operacional, eficiente retenção de biomassa, homogeneidade na mistura, estabilidade por um longo período de operação e estabilidade sob condições limitantes de substrato (STROUS et al., 1998; VAN DONGEN; JETTEN; VAN LOOSDRECHT, 2001).

Nesse sentido, trabalhos que visam ao enriquecimento e à produção de biomassa Anammox são importantes, pois podem viabilizar a aplicação dessa biomassa como inóculo para a partida de reatores Anammox que, posteriormente, poderão ser aplicados ao tratamento de águas residuárias contendo elevadas concentrações de amônia. $\mathrm{O}$ objetivo deste trabalho foi produzir biomassa Anammox a partir de lodo aeróbio proveniente de um sistema de lodos ativados, utilizando RBS. Pretendeu-se, ainda, obter maior compreensão do processo de enriquecimento e cultivo dessas bactérias.

\section{Material e métodos}

\section{Lodo de inóculo e meio de cultura}

Utilizou-se como inóculo (para o enriquecimento das Anammox) $650 \mathrm{~mL}$ de lodo proveniente do sistema convencional de lodos ativados da estação de tratamento de efluentes (ETE) Arrudas-Copasa, que trata esgoto doméstico da cidade de Belo Horizonte (MG). Esse lodo foi previamente centrifugado, de modo que o reator foi inoculado com 2,6 g de STV em 1 L de meio mineral autotrófico - composição 
descrita em Dapena-Mora et al. (2004) e Van de Graaf et al. (1996). $\mathrm{O}$ meio de cultura continha, inicialmente, $30 \mathrm{mg}$ de $\mathrm{N}_{-} \mathrm{NH}_{4}^{+} / \mathrm{L}$ e 30

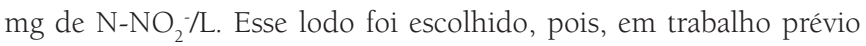
(ARAUJO; CHERNICHARO, 2007), verificou-se a presença de bactérias Anammox no mesmo, por meio da técnica da reação em cadeia da polimerase (PCR, do inglês polymerase chain reaction) com iniciadores específicos para esse grupo. Não obstante, esse lodo não apresentava atividade Anammox, tampouco foram detectadas essas bactérias por meio da técnica de FISH com aplicação da sonda Amx820.

\section{Operação do reator em batelada sequencial}

Um fermentador de vidro (BioFlo110, New Brunswick), com volume total de 1,2 L, foi usado para o enriquecimento e cultivo das bactérias Anammox. O fermentador possuía controle automático de temperatura (com manta aquecedora envolvendo o frasco de vidro), $\mathrm{pH}$, agitação, sensor de oxigênio dissolvido (OD) e sensores de nível para controlar a alimentação. O fermentador foi operado sob a forma de RBS, que consistiu de dois ciclos, cada um contendo três fases. O primeiro ciclo tinha a duração de 6 horas e 30 minutos e compreendeu: (i) fase de alimentação, na qual o meio mineral autotrófico (500 mL) foi introduzido no reator (com agitação contínua) ao longo de 5 horas e 30 minutos; (ii) fase de decantação (30 minutos), na qual a agitação do sistema foi desligada e permitiu-se a decantação da biomassa; (iii) fase de retirada do meio (foram retirados $500 \mathrm{~mL}$ ), que durava 30 minutos. O segundo ciclo durava cerca de 17 horas e 30 minutos, possuía as mesmas etapas do primeiro, com a diferença de que, após as 5 horas e 30 minutos de alimentação do reator, o meio de cultura continuava reagindo com a biomassa por cerca de 11 horas. Após esse tempo, foram realizadas as etapas de decantação e retirada do meio de cultura. O reator foi operado com tempo de detenção hidráulica (TDH) de 24 horas, volume útil de 1 L e retenção total de biomassa.

Ao longo da operação do reator, as concentrações de amônia e nitrito (afluente e efluente) eram monitoradas, a cada dois dias. A temperatura e o $\mathrm{pH}$ foram monitorados quatro vezes ao dia. $\mathrm{O}$ reator operou na temperatura de $34^{\circ} \mathrm{C}$ e pH $=7,5$ (com soluções de $\mathrm{NaOH}$ e $\mathrm{H}_{2} \mathrm{SO}_{4}$ acopladas a bombas peristálticas para corrigir o $\mathrm{pH}$ sempre que necessário). Para manter a anaerobiose do sistema (que era todo fechado), fluxionava-se a mistura de gás argônio e CO (95\%/5\%), 8 vezes ao dia (por 10 minutos) no meio líquido do reator, bem como na atmosfera do frasco de alimentação (afluente), contendo meio de cultura autotrófico. Após 30 dias do início de operação do fermentador, adicionou-se diariamente $1 \mathrm{~mL}$ de hidrazina e $1 \mathrm{~mL}$ de hidroxilamina (concentração final de $0,1 \mathrm{mM}$ ), diretamente no reator. De acordo com Third et al. (2005), como esses compostos são intermediários da reação Anammox, a presença deles no início da incubação pode ajudar a acelerar a reação e diminuir o tempo para enriquecer as bactérias.

Amônia e nitrito foram determinados colorimetricamente, de acordo com os métodos do fenato e sulfanílico, respectivamente descritos no Standard Methods for Analysis of Water and Wastewater (AWWA/APHA/WEF, 1998). A determinação da concentração de sólidos totais voláteis (STV) no lodo de inóculo também foi realizada de acordo com o AWWA/APHA/WEF (1998).

\section{Extração de DNA e reação em cadeia da polimerase com iniciadores para as Anammox}

O método de extração de DNA utilizado foi igual ao descrito por Egli et al. (2003), utilizando-se de 2 a 4 mL de lodo. Após a extração, a quantidade e integridade do DNA obtido foram estimadas em gel de agarose $1 \%$. Para a detecção e confirmação da presença das bactérias Anammox no lodo de inóculo e ao longo do enriquecimento, foram utilizados os seguintes pares de iniciadores (Tabela 1): Pla46F (forward) e reversos (Amx820R ou Amx1240R ou Amx667R). A condição de amplificação utilizada foi a mesma para todos os pares de iniciadores, exceto para o par An7F-An1388R, cuja amplificação seguiu o protocolo de Penton, Devol e Tiedje (2006). A amplificação consistiu de etapa inicial de desnaturação de 4 minutos a $94^{\circ} \mathrm{C}$, 35 ciclos que consistiram em 45 segundos de desnaturação a $94^{\circ} \mathrm{C}$, anelamento por 50 segundos a $56^{\circ} \mathrm{C}$, extensão por 1 minuto à $72^{\circ} \mathrm{C}$ e extensão final de 7 minutos a $72^{\circ} \mathrm{C}$. A presença e o tamanho dos produtos da PCR amplificados foram visualizados em gel de agarose $1 \%$, através da aplicação de uma alíquota de $5 \mu \mathrm{L}$ do produto da PCR. Após a eletroforese, o gel foi corado em solução com brometo de etídio, para permitir a visualização do DNA amplificado.

\section{Hibridação in situ fluorescente}

Para confirmar a presença das bactérias Anammox no lodo, bem como quantificar essa população, cerca de 2 a $10 \mathrm{~mL}$ de amostra

Tabela 1 - Iniciadores usados na reação em cadeia da polimerase para detecção de bactérias Anammox

\begin{tabular}{llll} 
Iniciador & Especificidade & Sequência (5' $\left.\rightarrow \mathbf{3}^{\prime}\right)$ & Referência \\
Pla46F & Planctomicetos & GGATTAGGCATGCAAGTC & Egli et al. (2001) \\
\hline Amx667R & Bactérias Anammox & ACCAGAAGTTCCACTCTC & Van der Star et al. (2007) \\
Amx820R & Gêneros Candidatus Brocadia e Candidatus Kuenenia & AAAACCCCTCTACTTAGTGCCC & Schmid et al. (2000) \\
Amx1240R & Candidatus Brocadia anammoxidans & TTTAGCATCCCTTTGTACCAACC & Schmid et al. (2000) \\
An7F & $\begin{array}{l}\text { Todos os organismos Anammox (Candidatus Brocadia, } \\
\text { Candidatus Kuenenia e Candidatus Scalindua) }\end{array}$ & GGCATGCAAGTCGAACGAGG & Penton, Devol e Tiedje (2006) \\
An1388R & & GCTTGACGGGCGGTGTG & Penton, Devol e Tiedje (2006)
\end{tabular}


do lodo ativado (inóculo), bem como da biomassa enriquecida no reator (após 184 dias de operação) foram fixados em solução de paraformaldeído 4\% em tampão fosfato de sódio (PBS $130 \mathrm{mM} \mathrm{NaCl}$, $7 \mathrm{mM} \mathrm{Na}_{2} \mathrm{HPO}_{4}, 3 \mathrm{mM} \mathrm{NaH}_{2} \mathrm{PO}_{4} ; \mathrm{pH}=7,2$ ). Posteriormente, essas amostras foram hibridadas com as sondas Amx820 (específica para Candidatus Brocadia anammoxidans e Candidatus Kuenenia stuttgartiensis) e Amx1240 (específica para Candidatus Brocadia anammoxidans), de acordo com o protocolo descrito por Egli et al. (2003), usando $40 \%$ de formamida (no tampão de hibridação) e 56 mM de $\mathrm{NaCl}$ (no tampão de lavagem). As sondas Nsol225 (MOBARRY et al., 1996), específicas para as oxidadoras de amônia da subclasse $\beta$-proteobacteria; Nit3 (WAGNER et al., 1996), específica para Nitrobacter e Ntspa662, para Nitrospira (DAIMS et al., 2000) também foram aplicadas na biomassa enriquecida, com o objetivo de investigar a presença das oxidadoras aeróbias da amônia e das oxidadoras de nitrito no RBS. Para essas sondas utilizou-se 35\% de formamida no tampão de hibridação. Após a hibridação, as amostras foram coradas com $10 \mu \mathrm{L}$ de uma solução de DAPI (4',6-diamidino-2-fenilindol), a $10 \mu \mathrm{g} / \mathrm{mL}$, e observadas em microscópio de fluorescência (BX-50, Olympus Corporation) equipado com câmera colorida refrigerada (Q-color5 ${ }^{\mathrm{TM}}$, Olympus Corporation). A porcentagem de células hibridadas com a sonda Amx1240 foi obtida calculando-se o número de células hibridadas com a sonda em relação ao número total de células coradas com DAPI. Foram contados cerca de 15 campos microscópicos (contendo aproximadamente 80 células por campo), e a contagem foi feita em duplicata.

\section{Resultados e discussão}

\section{Enriquecimento em reator em batelada sequencial}

A Figura 1 apresenta os resultados das concentrações de amônia e nitrito afluente e efluente, ao longo dos 210 dias de operação do reator. De acordo com os resultados obtidos e para permitir melhor compreensão do processo de enriquecimento, os perfis de concentração de amônia e de nitrito foram divididos em três fases. A fase 1 (com duração de 25 dias) correspondeu à fase inicial de operação do reator. Esta foi marcada pelo consumo intenso de nitrito sem que houvesse consumo de amônia; pelo contrário, houve aumento da concentração efluente desse composto (Figura 1). Nessa fase, portanto, a desnitrificação heterotrófica foi o processo favorecido (devido à atmosfera anaeróbia e à presença de nitrito usado como aceptor final de elétrons), eliminando a matéria orgânica presente no meio, oriunda da lise celular das bactérias aeróbias presentes no lodo de inóculo. A morte e lise dessas bactérias resultaram na liberação de nitrogênio orgânico e na quebra deste em amônia. A liberação de amônia no meio foi evidenciada pelos valores maiores de amônia efluente (em relação ao afluente), bem como pela eficiência de remoção negativa desse composto nos 25 dias iniciais. Após a lise das bactérias aeróbias, teve início a morte e a lise das bactérias desnitrificantes, devido à ausência de substratos orgânicos no meio, uma vez que o meio de cultura era autotrófico - sem fonte de carbono orgânico.

A fase 2, chamada de fase de propagação, durou cerca de 62 dias (do $25^{\circ}$ até o $87^{\circ}$ dia de operação). Essa fase foi marcada pela exaustão completa dos substratos orgânicos, resultando na diminuição e eliminação da atividade desnitrificante. As concentrações de nitrito efluente nessa fase foram próximas às concentrações afluentes, indicando que esse aceptor final de elétrons não estava mais sendo utilizado. A partir desse momento, as condições do sistema (anaerobiose, meio autotrófico, $\mathrm{pH}=7,5$ etc.) devem ter favorecido o aumento da população Anammox. Esse aumento culminou no aparecimento da atividade Anammox, marcada pelo consumo simultâneo de amônia e de nitrito, detectada no final da fase 2 , a partir do $87^{\circ}$ dia de operação (Figura 1). De acordo com a literatura (DAPENA-MORA et al., 2004; THIRD et al., 2005; CHAMCHOI; NITISORAVUT, 2007), o início da atividade Anammox em RBS pode acontecer após 70 a 120 dias de

Figura 1 - Concentração afluente e efluente dos compostos nitrogenados e eficiência de remoção de amônia $\left(\mathrm{N}^{-} \mathrm{NH}_{4}^{+}\right)$e nitrito $\left(\mathrm{N}^{-} \mathrm{NO}_{2}^{-}\right)$pelo lodo cultivado no reator em batelada sequencial ao longo do tempo de operação. 
operação. Portanto, o sistema começou a responder de acordo com o que foi observado em outros trabalhos. Durante a fase de propagação, a eficiência de remoção de amônia variou de 0 a 50\% (Figura 1), indicando pequeno consumo desse composto.

A fase 3 correspondeu à última fase do cultivo e foi chamada de fase Anammox (considerada a partir do $87^{\circ}$ dia de operação). Nessa fase a reação Anammox foi intensa e permitiu remoção quase completa de amônia no sistema. Nesse período as concentrações de amônia e nitrito efluente variaram de 0 a 10 mg/L (Figura 1). A partir do $125^{\circ}$ dia de operação, as concentrações de amônia e nitrito foram aumentadas gradativamente, sempre respeitando a relação de 1:1,26 $\left(\mathrm{NH}_{4}^{+}\right.$: $\left.\mathrm{NO}_{2}^{-}\right)$. Nessa mesma fase a eficiência de remoção de amônia e nitrito por parte da biomassa enriquecida foi aumentando, atingindo cerca de 95\% (Figura 1). A eficiência de remoção de amônia, observada neste trabalho, foi relativamente alta quando comparada com dados da literatura. Trabalhos prévios indicaram eficiência de remoção de amônia de 84, 88, 40 e 80\% para reator de leito fluidizado (STROUS et al., 1997), leito fixo (STROUS et al., 1997), reator de leito granular expandido (WANG; KANG, 2005) e RBS (CHAMCHOI; NITISORAVUT, 2007), alimentados com meio sintético, respectivamente.

O coeficiente estequiométrico de consumo de nitrito em relação à amônia, calculado a partir dos dados do RBS (Figura 2) e do $87^{\circ}$ dia de operação, foi relativamente próximo ao valor descrito na literatura para a reação Anammox $\left(\mathrm{NH}_{4}^{+}: \mathrm{NO}_{2}^{-}: 1:\right.$ 1,32) (STROUS et al., 1998). Isso demonstra que o lodo ativado após 87 dias de cultivo em meio autotrófico e anaeróbio desenvolveu atividade Anammox.

Em comparação com outros trabalhos, o tempo observado no presente estudo para o enriquecimento da biomassa Anammox (cerca de 90 dias) foi relativamente menor. Van de Graaf et al. (1996) conseguiram biomassa Anammox após sete meses de cultivo em um sistema com biomassa aderida. Egli et al. (2001) levaram seis meses para enriquecer uma cultura Anammox com $88 \%$ de pureza, a partir de inóculo com atividade Anammox prévia. Toh, Webb e Ashbolt (2002) relataram crescimento de biofilme após um ano de operação em reator de leito fixo que apresentava atividade Anammox. Toh, Webb e Ashbolt (2002) observaram atividade Anammox após 15 meses de adaptação e enriquecimento em reator de leito fixo tratando água residuária sintética, simulando efluente de coqueria. Chamchoi e Nitisoravut (2007) enriqueceram biomassa Anammox a partir de diferentes lodos (aeróbio e anaeróbio) após quatro meses de operação em RBS.

O desempenho do reator ao longo dos sete meses de operação demonstrou remoção quase total de nitrito baseada em concentração afluente de 61 a $95 \mathrm{mg} \mathrm{N}-\mathrm{NO}_{2}^{-} / \mathrm{L}$. A eficiência máxima de remoção de amônia alcançada foi de $95 \%$ a partir de concentração afluente de 55 a $82 \mathrm{mg} \mathrm{N}-\mathrm{NH}_{4}^{+} / \mathrm{L}$. Os resultados indicam que essa biomassa poderia ser utilizada no pós-tratamento de efluentes de reatores anaeróbios de fluxo ascendente (UASB, do inglês upflow anaerobic sludge blanket reactor) (tratando esgoto doméstico), por exemplo, para remover o nitrogênio amoniacal (cerca de $40 \mathrm{mg} / \mathrm{L}$ ) presente nesses efluentes. Além disso, a operação do RBS com concentrações cada vez maiores de nitrito e amônia poderia levar à adaptação dessa biomassa a concentrações altas de amônia (de 1.200 mg/L, por exemplo), de modo a

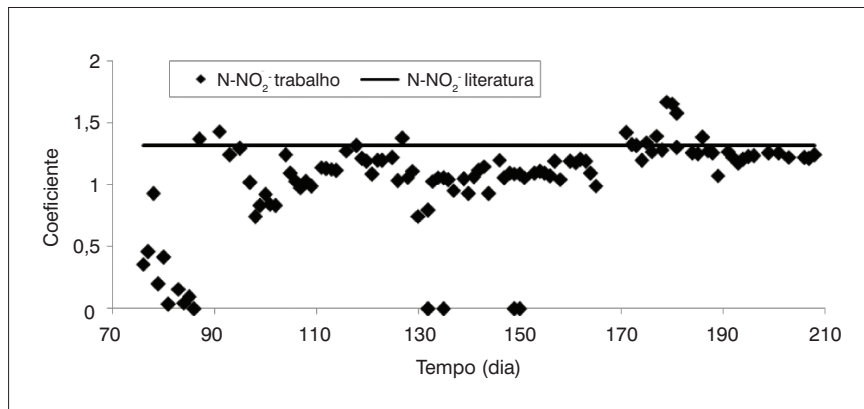

Figura 2 - Coeficiente estequiométrico do nitrito em relação à amônia (N-NO $-/ \mathrm{N}_{2} \mathrm{NH}_{4}^{+}$), de acordo com os dados de consumo de nitrogênio do reator obtidos neste trabalho.

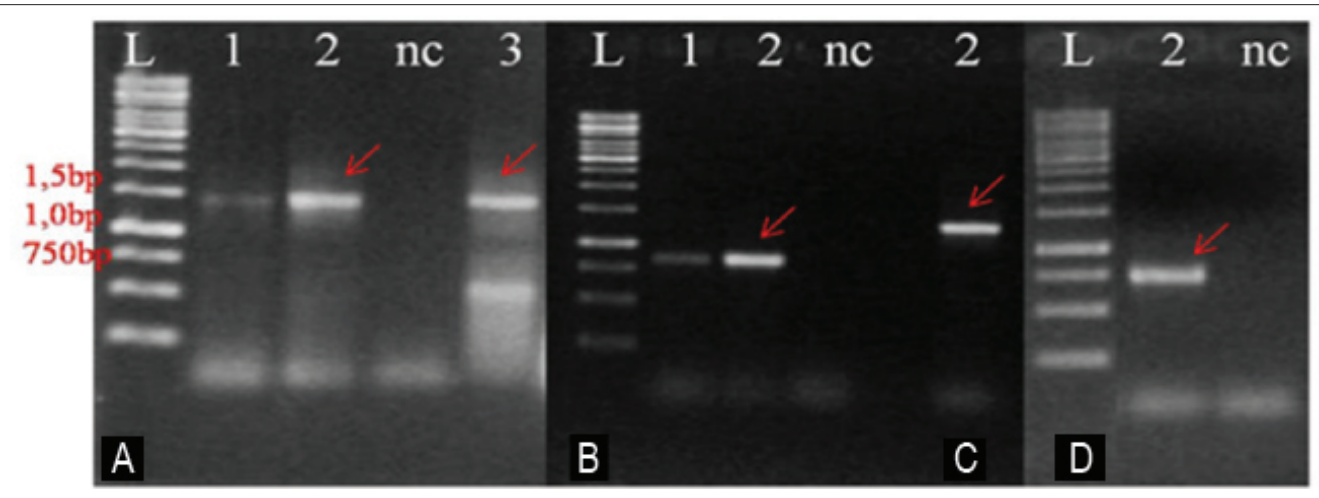

Figura 3 - Detecção pela reação em cadeia da polimerase do DNAr 16S de Anammox, amplificados com diferentes iniciadores: An7F e An1388R (A), Pla46F e Amx820R (B); Pla46F e Amx1240R (C); Pla46F e Amx667R (D). L: marcador de peso molecular (1Kb-Kilobases- Fermentas); (1) Biomassa do reator em batelada sequencial após 184 dias de enriquecimento (DNA diluído 10 vezes); (2) Biomassa do reator em batelada sequencial após 184 dias (DNA concentrado); (3) Lodo ativado usado como inóculo; nc: controle negativo da reação (sem DNA); bp: pares de bases (do inglês base pair). Para a especificidade dos iniciadores, consultar a Tabela 1. Os fragmentos correspondentes ao DNAr16S de Anammox estão indicados pelas setas. 
verificar a viabilidade do processo Anammox no tratamento de águas residuárias contendo altas concentrações de nitrogênio amoniacal e baixas concentrações de matéria orgânica, como é o caso do lixiviado de aterro sanitário.

\section{Confirmação da presença das bactérias Anammox pela técnica da reação em cadeia da polimerase}

Os resultados da PCR com iniciadores específicos para as Anammox demonstraram a presença de DNAr 16S dessas bactérias tanto no lodo de inóculo, quanto na biomassa enriquecida no RBS após 184 dias de cultivo em meio autotrófico e anaeróbio (Figura 3). Uma vez que o DNA da biomassa cultivada apresentou produto da PCR com a mesma intensidade do produto amplificado a partir do DNA do lodo ativado (inóculo) e o controle negativo (sem DNA) não apresentou qualquer sinal (Figura $3 \mathrm{~A}$ ), pode-se sugerir que as bactérias Anammox estavam presentes no lodo ativado antes do experimento de eriquecimento.

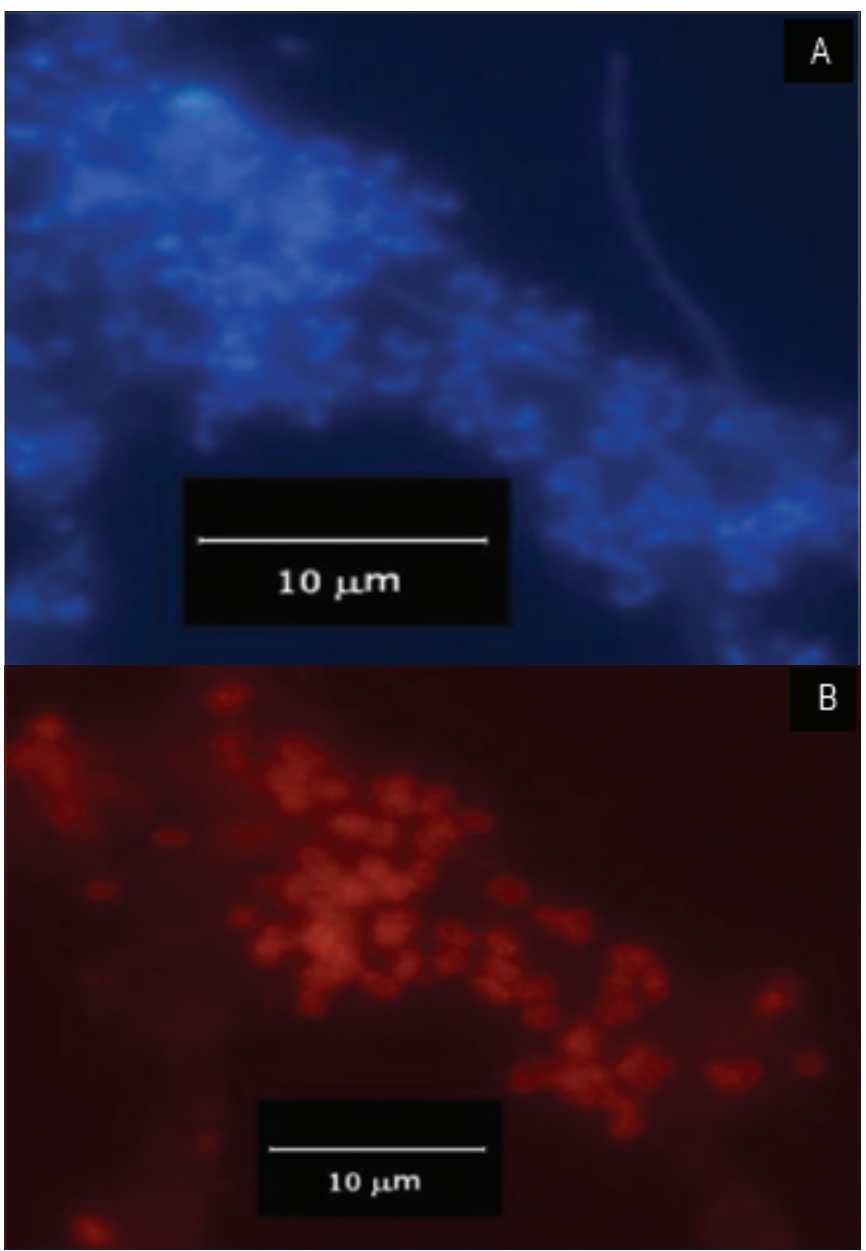

Figura 4 - Análise da hibridação in situ fluorescente da biomassa enriquecida no reator em batelada sequencial após 184 dias de cultivo. (A) amostra corada com DAPI (4',6-diamidino-2-phenylindole); (B) amostra hibridada com a sonda Amx1240 (específica para Candidatus Brocadia anammoxidans).

\section{Confirmação da presença de Anammox por hibridação in situ fluorescente}

Os resultados das análises de FISH com a biomassa enriquecida no RBS, após 184 dias de cultivo, confirmaram a presença de bactérias Anammox (provavelmente Candidatus brocadia anammoxidans) nesse lodo, pois as células hibridaram com as sondas Amx820 (dados não apresentados) e Amx1240 (Figura 4). A quantificação por meio da contagem do número de células hibridadas com a sonda Amx1240 revelou que $52,7 \%( \pm 15,6)$ do total de células do enriquecimento eram bactérias Anammox. Conforme descrito previamente para Candidatus brocadia anammoxidans (STROUS, 2000), as células de Anammox enriquecidas no presente trabalho também apresentaram morfologia arredondada, com aproximadamente 1,2 $\mu \mathrm{m}$ de diâmetro, e uma região escura (sem fluorescência) no centro da célula (Figuras 4A e 4B, respectivamente). Essa área central, sem ribossomos e DNA (pois não corou com DAPI), deve ser provavelmente uma região rica em proteína, similar ao anammoxossomo de Candidatus brocadia anammoxidans. É importante observar também que no lodo enriquecido foram encontradas bactérias filamentosas coexistindo com as Anammox (Figura 4A). Não foi verificado sinal positivo de hibridação com as sondas Nso1225 (específica para as oxidadoras aeróbias de amônia), Nit3 (específica para Nitrobacter) e Ntspa662 (específica para Nitrospira), sugerindo que essas bactérias não estavam presentes na biomassa enriquecida.

\section{Conclusões}

O lodo aeróbio proveniente de um sistema convencional de lodos ativados tratando esgoto doméstico foi um bom inóculo para se obter e enriquecer bactérias Anammox, apesar de não possuir previamente atividade Anammox. Esse lodo desenvolveu atividade Anammox após 87 dias de cultivo em meio autotrófico e anaeróbio em RBS, operado com TDH de 24 horas.

O processo de enriquecimento e cultivo pode ser dividido em três fases: fase 1 (duração de 25 dias), caracterizada pela atividade desnitrificante; fase 2 (duração de 62 dias), período de propagação das células Anammox; fase 3, marcada por intensa atividade Anammox.

A presença das bactérias Anammox foi confirmada através das técnicas de PCR e FISH. As células do enriquecimento hibridaram com as sondas Amx820 e Amx1240, indicando que são bactérias Anammox (provavelmente, Candidatus Brocadia anammoxidans). Não obstante, a identificação filogenética dessa cultura - a partir do sequenciamento e análise comparativa do DNAr 16S - será realizada.

A operação do RBS por sete meses permitiu atingir uma boa concentração de bactérias Anammox na biomassa enriquecida, ou seja, cerca de 53\% do total de células do lodo cultivado eram Anammox. Não obstante, a operação do RBS por mais tempo permitirá aumentar essa população. Posteriormente, essa cultura poderá ser usada como inóculo para a partida de reatores Anammox, que poderão ser usados 
no tratamento de águas residuárias contendo concentrações altas de nitrogênio amoniacal.

\section{Agradecimentos}

Os autores agradecem aos órgãos fomentadores: Conselho Nacional de Desenvolvimento Científico e Tecnológico (CNPq), por meio do Edital Universal 471830/2006-2, Fundação de Amparo à Pesquisa de Minas Gerais (Fapemig) (TEC 946-06) e Finep (Rede Prosab Microbiologia) pelo financiamento da pesquisa. Os autores também agradecem o apoio da Copasa em fornecer o lodo proveniente da ETE Arrudas (Belo Horizonte, MG).

\section{Referências}

AWWA/APHA/WEF. Standard methods for the examination of water and wastewater, 20 ${ }^{\text {th }}$ ed. Washington, DC: APHA, 1998.

ARAUJO, J.C.; CHERNICHARO, C.A.L. Detection of anaerobic ammonium-oxidizing bacteria in different sludges and in a landfill leachate sample. In: $11^{\text {th }}$ World Congress on Anaerobic Digestion (IWA), Brisbane. Conference CD. Oral program. Brisbane: IWA, 2007, PP4C.3, p. 1-8.

CHAMCHOI N.; NITISORAVUT S. Anammox enrichment from different conventional sludges. Chemosphere, v. 66, n. 11, p. 2225-2232, 2007.

DAIMS, $\mathrm{H}$. et al. Novel Nitrospira-like bacteria as dominant nitriteoxidizers in biofilms from wastewater treatment plants: diversity and in situ physiology. Water science and technology, v. 41, n. 4-5, p. 85-90, 2000

DALSGAARD, T.; THAMDRUP, B. Factors controlling anaerobic ammonium oxidation with nitrite in marine sediments. Applied and Environmental Microbiology, v. 68, n. 8, p. 3802-3808, 2002.

DAPENA-MORA, A. et al. Enrichment of anammox biomass from municipal activated sludge: experimental and modeling results. Journal of Chemical Technology and Biotechnology, v. 79, p. 1421-1428, 2004.

EGLI, K. et al. Community analysis of ammonia and nitrite oxidizers during start-up of nitritation reactors. Applied and Environmental Microbiology, v. 69, n. 6, p. 3213-3222, 2003.

Enrichment and characterization of an anammox bacterium from a rotating biological contactor treating ammonium-rich leachate. Archives Microbiology, v. 175, n. 3, p. 198-207, 2001.

JETTEN, M.S. et al. Anaerobic ammonium oxidation by marine and freshwater planctomycete-like bacteria. Applied Microbiology and Biotechnology, v. 63, n. 2, p. 107-114, 2003.

KARTAL, B. et al. Candidadtus "Anammoxoglobus propionicus" a new propionate oxidizing species of anaerobic ammonium oxidizing bacteria. Systematic and Applied Microbiology, v. 30, n. 1, p. 39-49, 2007.

MOBARRY, B.K. et al. Phylogenetic probes for analyzing abundance and spatial organization of nitrifying bacteria. Applied and Environmental Microbiology, v. 62, n. 6, p. 2156-2162, 1996.
MULDER, A. et al. Anaerobic ammonium oxidation discovered in a denitrifying fluidized bed reactor. FEMS Microbiology Ecology, v. 16, n. 3, p. 177-184, 1995

PENTON, C.R.; DEVOL, A.H.; TIEDJE, J.M. Molecular Evidence for the broad distribution of anaerobic ammonium-oxidizing bacteria in freshwater and marine sediments. Applied and Environmental Microbiology, v. 72, n. 10, p. 6829-6832, 2006.

QUAN, Z.X. et al. Diversity of ammonium-oxidizing bacteria in a granular sludge anaerobic ammonium-oxidizing (anammox) reactor Environmental Microbiology, v. 10, n. 11, p. 3130-3139, 2008.

SÀNCHEZ-MELSIÓ, A. et al. Development of batch-culture enrichment coupled to molecular detection for screening of natural and man-made environments in search of anammox bacteria for $\mathrm{N}$-removal bioreactors systems. Chemosphere, v. 75, n. 2, p. 169-179, 2009.

SCHMID, M.C. et al. Biomarkers for in situ detection of anaerobic ammonium-oxidizing (anammox) bacteria. Applied and Environmental Microbiology, v. 71, n. 4, p.1677-1684, 2005.

Candidatus "Scalindua brodae", sp. nov., Candidatus "Scalindua wagneri", sp. nov., two new species of anaerobic ammonium oxidizing bacteria. Systematic and Applied Microbiology, v. 26, n. 4, p. 529-538, 2003

Molecular evidence for genus level diversity of bacteria capable of catalyzing anaerobic ammonium oxidation. Systematic and Applied Microbiology, v. 23, n. 1, p. 93-106, 2000

SCHUBERT, C.J. et al. Anaerobic ammonium oxidation in a tropical freshwater system (Lake Tanganyika). Environmental Microbiology, v. 8 , n. 10 , p. $1857-1863,2006$

STROUS, M. Microbiology of anaerobic ammonium oxidation. PhD thesis, Technical University Delft (The Netherlands), 2000

The sequencing batch reactor as a powerful tool for the study of slowly growing anaerobic ammonium-oxidizing microorganisms. Applied Microbiology and Biotechnology, v. 50, p. 589-596, 1998.

Ammonium removal from concentrated waste streams with the anaerobic ammonium oxidation (Anammox) process in different reactor configurations. Water Research, v. 31, n. 8, p. 1955-1962, 1997

TAL, Y.; WATTS, J.E.; SCHREIER, H.J. Anaerobic ammonia-oxidizing bacteria and related activity in Baltimore inner harbor sediment. Applied and Environmental Microbiology, v.71, n. 4, p. 1816-1821, 2005.

THIRD, K.A. et al. Enrichment of anammox from activated sludge and its application in the CANON Process. Microbial Ecology, v. 49, n. 2, p. 236-244, 2005.

TOH, S.K.; ASHBOLT, N.J. Adaptation of anaerobic ammonium-oxidising consortium to synthetic coke-ovens wastewater. Applied Microbiology and Biotechnology, v. 59, n. 2-3, p. 344-352, 2002

TOH, S.K.; WEBB, R.I.; ASHBOLT, N.J. Enrichment of autotrophic anaerobic ammonium-oxidizing consortia from various wastewaters. Microbial Ecology, v. 43, n. 1, p. 154-167, 2002 
VAN DE GRAAF, A.A. et al. Autotrophic growth of anaerobic ammoniumoxidizing microorganisms in a fluidized bed reactor. Microbiolology, $\mathrm{v}$. 142, p. 2187-2196, 1996.

VAN DER STAR, W.R. et al. Startup of reactors for anoxic ammonium oxidation: experiences from the first full-scale anammox reactor in Rotterdam. Water Research, v. 41, n. 18, p. 4149-4163, 2007.

VAN DONGEN, U.; JETTEN, M.S.; VAN LOOSDRECHT, M.C. The SHARON-Anammox process for treatment of ammonium rich wastewater. Water Science and Technology, v. 44, n. 1, p. 153-160, 2001
VAN NIFTRIK, L.A. et al. The anammoxosome: an intracytoplasmic compartment in anammox bacteria. FEMS Microbiology Letters, v. 233 n. 1, p. 7-13, 2004.

WAGNER, M. et al. In situ analysis of nitrifying bacteria in sewage treatment plants. Water Science and Technology, v. 34, p. 237-244, 1996.

WANG, J.; KANG, J. The characteristics of anaerobic ammonium oxidation (Anammox) by granular sludge from an EGSB reactor. Process Biochemistry, v. 40, n. 5, p. 1973-1978, 2005. 